\title{
Familial cutaneous photosensitivity and colitis with lethal outcome
}

\author{
Ph Labrune, P Huguet, D Alagille, M Odievre
}

\begin{abstract}
Three sibs out of four, born to unrelated parents, developed early cutaneous photosensitivity and severe colitis. All of them died from untreatable diarrhoea. A fourth boy, whose father was different, did not have the same symptoms. The origin of this syndrome remains unclear and, in particular, no metabolic defect could be detected.
\end{abstract}

The association of colitis and cutaneous photosensitivity has rarely been reported and such an association is not known to be hereditary. We report on a family in whom three out of four children were affected by early cutaneous photosensitivity and severe colitis with lethal outcome. The origin of this syndrome is still to be determined.

\section{Case reports}

FAMILY HISTORY

An unrelated, healthy couple had three affected children (cases 1, 2, and 3). With another partner, the mother had a fourth boy, born between cases 2 and 3 . Soon after his birth, his mother predicted that this infant would not be affected by the same disease, since his father was different. This boy developed normally and is now a 9 year old normal boy.

\section{CASE 1}

The boy was the first child, born in June, after a 36 week, uneventful pregnancy, birth weight $2150 \mathrm{~g}$. At the age of 2 weeks, he presented with facial erythematous and vesicular lesions after a six hour

Service de Pédiatrie Générale, Hôpital Antoine Béclère, 157 rue de la Porte de Trivaux, 92141 Clamart Cedex, France.

Ph Labrune, $\mathrm{P}$ Huguet, $M$ Odievre

Service d'Hépatologie, Département de Pédiatrie, Hôpital Bicêtre, 94275 Le Kremlin Bicêtre Cedex, France. D Alagille

Correspondence to Dr Labrune.

Received for publication 8 March 1990

Revised version accepted for publication 11 July 1990. exposure to sun. The infant was given local corticosteroid therapy and the lesions disappeared within eight days. The same facial lesions recurred after exposure to the sun at the age of 6 and 10 weeks; their evolution was similar to that of the first episode. He was admitted to hospital at the age of 5 months because of failure to thrive (weight $5150 \mathrm{~g}$ ). Physical examination noted erythematous and squamous lesions on his chest and buttocks. The infant was pale and hypotonic. The liver and spleen were not enlarged and the temperature was $37^{\circ} \mathrm{C}$. Stools were frequent, liquid, and bloody. Complete blood cell count and serum electrolytes were normal; stool cultures yielded Staphylococcus aureus. Enteral feeding was stopped for three days and replaced by intravenous fluids and the bloody stools disappeared. During the following three weeks, vomiting and bloody stools recurred every time enteral feeding was reintroduced. He was then transferred to a specialist unit: his weight was $4375 \mathrm{~g}$, the temperature was $35^{\circ} 8 \mathrm{C}$, and the systolic blood pressure was $50 \mathrm{mmHg}$. Oedema was noted in the feet and legs and the infant was found to bruise easily. His abdomen was distended. Coagulation was normal. Hypoproteinaemia (36 g/l) and hypoalbuminaemia $(20 \mathrm{~g} / \mathrm{l})$ were noted. Complete blood cell count and serum electrolytes were normal (apart from hypocalcaemia related to hypoalbuminaemia). The infant was given antibiotics (penicillin and colimycin) despite negative blood and stool cultures, repeated infusions of albumin and plasma, and was fed with human milk provided by a bank. Within two weeks, his clinical symptoms improved (disappearance of bloody stools, weight gain up to $5100 \mathrm{~g}$, regression of oedema) and proteinaemia rose to $56 \mathrm{~g} / \mathrm{l}$ and albuminaemia to $31 \mathrm{~g} / \mathrm{l}$. Four days later, the abdomen was again found to be distended, the stools were bloody, bilateral pneumonia developed, and the infant died at the age of 6 months. At necropsy, the oesophagus, stomach, duodenum, and small intestine were normal. The colonic walls were thickened and the mucosa was fragile and congested; no ulceration was found. The lungs showed scattered areas of infection. The liver was normal.

On light microscopic examination the colonic mucosa appeared congested and hypersecretory; in scattered areas, the surface epithelium was cuboidal with shorter crypts composed of degenerating cells. 
The mucosa was infiltrated by lymphocytes and plasmocytes. The submucosa contained thickened collagenous fibres. The small intestine and the liver were normal.

\section{CASE 2}

This girl was born after an uneventful term pregnancy, weighing $2400 \mathrm{~g}$, one year after the death of case 1 . During the first year of life, she presented with three episodes of sun-induced facial erythematous and vesicular lesions, similar to those previously observed in her brother. She was first admitted to hospital at the age of 13 months when she presented with bloody diarrhoea and mucus. Her weight was $6740 \mathrm{~g}$ and her height was $75 \mathrm{~cm}$. Physical examination was normal. Complete blood cell count and serum electrolytes were normal. Repeated blood and stool cultures were negative. Liver tests were normal. Rectosigmoidoscopy showed diffuse fragile and haemorrhagic mucosa but no ulceration was noted; rectal biopsies were histologically normal. No colonoscopy was performed. Upper gastrointestinal examination with a small bowel follow through showed alternating narrow and dilated areas. Porphyria was excluded by urine, blood, and stool analysis. Vitamin B6 plasma concentration was $10 \mathrm{ng} / \mathrm{ml}$ (normal 4 to 17 $\mathrm{ng} / \mathrm{ml}$ ). Blood and urine amino acid chromatograms were normal. Tryptophan loading test $(20 \mathrm{mg} / \mathrm{kg}$, orally) was also normal. Anti-DNA and anti-colon autoantibodies were not found in the serum. The infant was treated with salazopyrin and clinical symptoms disappeared within 10 days. Two months later, rectosigmoidoscopy and upper gastrointestinal examination proved normal and the infant was discharged with no treatment. She was readmitted six months later with watery, bloody diarrhoea, her weight was $7920 \mathrm{~g}$ (-2 SD), and her height was $76 \mathrm{~cm}$ (-1 SD). Apart from palmar erythrosis and dry and fragile hair, physical examination proved normal. Blood cell count and serum electrolytes were normal. She was given a daily oral dose of pyridoxine $(50 \mathrm{mg})$. A second tryptophan oral loading test was performed ( $50 \mathrm{mg} / \mathrm{kg} \mathrm{L-tryptophan)} \mathrm{and} \mathrm{the} \mathrm{results} \mathrm{were} \mathrm{normal}$ again (in particular the excretion of kynurenine, kynurenic acid, hydroxykynurenine, anthranilic acid, nicotinic acid, and 5HIAA). Despite treatment, the diarrhoea continued with blood and mucus and the infant died at the age of 20 months. At necropsy, the small intestine was normal; the colonic walls were thickened and the mucosa was inflamed with petechial bleeding and increased visible mucus. No macroscopic ulceration was found. Pulmonary oedema was also noted.

On light microscopic examination, the mucosa of the colon showed infiltration of lymphocytes and red blood cells; in some areas, there was a loss of surface epithelium with accumulation of polynuclear cells. The submucosa contained diffuse areas of haemor- rhage around damaged blood vessels. The small intestine was normal.

CASE 3

Four years after case 2 died, this boy was born in May, weighing $2580 \mathrm{~g}$, after a 36 week pregnancy. At the age of 2 months, he presented with sun induced cutaneous symptoms similar to those previously observed in cases 1 and 2 . He was first admitted to hospital at the age of 6 months with bloody and watery diarrhoea. His weight was $6450 \mathrm{~g}$ and his height was $65 \mathrm{~cm}$; physical examination proved normal. Serum electrolytes, complete blood cell count, and liver tests were normal. Upper gastrointestinal examination, barium enema, and rectosigmoidoscopy were also normal. The infant was placed on a lactose free diet and the diarrhoea disappeared within a week. At this time, the infant was phototested with a xenon arc solar simulator $(150$ watts). The minimal erythema dose to combined UVB and UVA radiation was $\mathbf{0 . 6}$ minutes (normal ranging from one to four minutes of exposure, depending on skin type). There was an erythematous and papular response at 24 hours. Skin biopsy showed nonspecific dermatitis, as observed in photosensitivity, irrespective of its origin.

At the age of 10 months, the infant was readmitted with fever $\left(40^{\circ} \mathrm{C}\right)$, watery and bloody diarrhoea, and weight loss $(6950 \mathrm{~g})$. He was tired and pale and his abdomen seemed painful. Rectosigmoidoscopy proved normal. Serum protein concentration was $\mathbf{4 0}$ g/l with hypoalbuminaemia (22 $\mathrm{g} / \mathrm{l})$; coagulation, blood cell count, and liver tests were normal. The infant was given antibiotics, albumin infusions, salazopyrin, and cholestyramine, and was placed on a gluten and lactose free diet. Clinical symptoms disappeared within three weeks. During this period, a tryptophan loading test $(50 \mathrm{mg} / \mathrm{kg}$ of L-tryptophan orally) was performed and the results were normal. Erythrocytic protoporphyrin was $60 \mu \mathrm{g} / 100 \mathrm{ml}$ of erythrocytes (normal $<100$ ) and urinary porphyrin excretion was $0.28 \mu \mathrm{mol} /$ day (normal $<0.35$ ). Antismooth muscle, anti-liver, anti-thyroid, antinuclear, and anti-DNA autoantibodies were not found in the serum. Serum IgG was $12 \mathrm{~g} / \mathrm{l}$, IgA $2.5 \mathrm{~g} / \mathrm{l}$, and IgM $0.8 \mathrm{~g} / \mathrm{l}$. The karyotype was normal. The infant was discharged at the age 14 months (weight $7900 \mathrm{~g}$ ), still being fed a lactose and gluten free diet. He was growing well on this diet and his psychomotor development was considered to be normal (IQ 100 on the Stanford Binet scale at the age of 24 months). He never had cerebellar ataxia. He was readmitted at the age of 32 months with bloody diarrhoea and weight loss (1800 $\mathrm{g}$ within a week). Rectosigmoidoscopy showed fragile and congestive mucosa with scattered areas of blood suffusion. Rectal biopsies indicated interstitial inflammatory proctitis with no ulceration. 
White blood cell count was $10000 / \mathrm{mm}^{3}$ with $35 \%$ neutrophils and $60 \%$ lymphocytes; platelet count was $250000 / \mathrm{mm}^{3}$, and haemoglobin was $11.5 \mathrm{~g} / \mathrm{dl}$. Serum electrolytes and transaminases were normal. Plasma zinc concentration was $80 \mu \mathrm{g} / 100 \mathrm{ml}$ (normal $>68 \mu \mathrm{g} / \mathrm{ml}$ ) while no zinc supplementation was prescribed. The child was given oral prednisone $(2 \mathrm{mg} / \mathrm{kg} / \mathrm{day})$ and repeated enemas with salazopyrin and corticoids. Within a few days the diarrhoea disappeared. A second tryptophan loading test was performed $(50 \mathrm{mg} / \mathrm{kg})$ and results were normal again. Oral prednisone was continued, together with diet and salazopyrin enemas, and the child was discharged.

He was readmitted two months later with extensive and severe chickenpox. Despite treatment, the child died from cardiovascular collapse. Permission for necropsy was refused.

\section{Discussion}

Our three patients had cutaneus photosensitivity (proved by phototesting in case 3) and recurring severe colitis with lethal outcome. Despite repeated examinations, the origin of these symptoms was not found. This syndrome is likely to have been transmitted as an autosomal recessive trait: neither parent had ever shown photosensitivity nor digestive troubles and a healthy child was born from a different father. No examination was performed on the parents or the normal child.

Several diseases have already been described which include symptoms similar to those of our patients. Acrodermatitis enteropathica comprises bullous skin rash, diarrhoea, and fatal outcome. In the first two patients plasma zinc concentration was not performed; however, the normal plasma zinc concentration in case 3 strongly argues against the diagnosis of acrodermatitis enteropathica.

Hartnup disease is characterised by a sensitive pellagra-like rash, cerebellar ataxia, emotional instability, and aminoaciduria. ${ }^{1}$ Our patients had no cerebellar ataxia and their urinary amino acid chromatograms were always normal; furthermore, colitis is not part of Hartnup disease. Hydroxykynureninuria is a rare disorder of tryptophan metabolism comprising blood diarrhoea in infancy, haemolytic anaemia, mental retardation, short stature, and urinary excretion of large amounts of xanthurenic acid, kynurenine, and 3-hydroxykynurenine. ${ }^{2}$ Tada $e t a^{3}$ reported a case whose clinical symptoms were similar to those of hydroxykynureninuria; the patient excreted large amounts of tryptophan and indoleacetic acid. These two metabolic disorders did not cause death and tryptophan loading tests were normal in cases 2 and 3 , excluding an inborn error of tryptophan metabolism. Actinic reticuloid, a chronic, light induced dermatitis associated with alterations in tryptophan metabolism, occurs predominantly in elderly men and does not include digestive symptoms. ${ }^{4}$

Photodermatoses are uncommon in children, except for ordinary overexposure reactions to sunlight. ${ }^{5}$ Idiopathic disorders, such as neonatal lupus erythematosus (antinuclear and anti-DNA antibodies), polymorphous light eruption, and solar urticaria (which do not include digestive symptoms), were excluded in our patients as were genetic photodermatoses such as the porphyrias, xeroderma pigmentosum, ataxia telangiectasia, and Bloom's syndrome. ${ }^{5}$

Cutaneous disorders are commonly associated with inflammatory bowel disease (IBD) ${ }^{6}$ This condition normally begins during adolescence and not during infancy and comprises ulcerative colitis and Crohn's disease. These diseases were ruled out in our patients. Predisposition to IBD in certain families and ethnic groups has been documented previously, ${ }^{7}$ but IBD has never been reported in three out of four sibs in a family. Furthermore, cutaneous changes associated with IBD comprise erythema nodosum and pyoderma gangrenosum in particular, and photosensitivity has not yet been reported. ${ }^{6}$

Finally, animal models of ulcerative colitis after skin sensitisation of guinea pigs or rabbits with dinitrochlorobenzene have been described (related to cellular immune response) ${ }^{8}$ The only local therapies that our patients ever received were antiseptics (with no dinitrocholobenzene) and corticosteroids.

Therefore, our patients seem to have a syndrome separate from tryptophan metabolism alterations, photodermatoses or cutaneous disorders associated with IBD. Whether an underlying metabolic defect may be the the cause of this syndrome remains to be determined.

1 Jepson JB. Hartnup disease. In: Stanbury JB, Wyngaarden JB, Fredrickson DS, eds. The metabolic basis of inherited diseases. 4th ed, New York: McGraw-Hill. 1978:1563-77.

2 Komrower GM, Westall R. Hydroxykinureninuria. Am $\mathcal{J}$ Dis Child 1967;113:77-80.

3 Tada K, Ito H, Wada Y, Arakawa T. Congenital tryptophanuria with dwarfism. Tohoku $\mathcal{F}$ Exp Med 1963;80:118-34.

4 Vonderheid EC, Sobel EL, Hoeldtke RD, Faerber GJ, Sardi VS. Kynurenic acid and xanthurenic acid excretion after tryptophan loading in actinic reticuloid. Int $\mathcal{f}$ Dermatol 1987;26:33-41.

5 Kahn G. Photosensitivity and photodermatitis in childhood. Dermatol Clin 1986;4:107-16.

6 Paller AS. Cutaneous changes associated with inflammatory bowel disease. Pediatr Dermatol 1986;3:439-45.

7 Lashner BA, Evans AA, Kirsner JB, Hanauer SB. Prevalence and incidence of inflammatory bowel disease in family members. Gastroenterology 1986;91:1396-400.

8 McPherson B, Pfeiffer CJ. Experimental colitis. Digestion 1976; 14:424-52. 